\title{
AFF3 upregulation mediates tamoxifen resistance in breast cancers
}

\author{
Yawei Shi ${ }^{1 \dagger}$, Yang Zhao ${ }^{2 \dagger}$, Yunjian Zhang ${ }^{1}$, NiJiati AiErken ${ }^{3}$, Nan Shao ${ }^{1}$, Runyi Ye ${ }^{1}$, Ying Lin ${ }^{1 *}$ \\ and Shenming Wang ${ }^{1 *}$
}

\begin{abstract}
Background: Although tamoxifen is a highly effective drug for treating estrogen receptor-positive $\left(E R^{+}\right)$breast cancer, nearly all patients with metastasis with initially responsive tumors eventually relapse, and die from acquired drug resistance. Unfortunately, few molecular mediators of tamoxifen resistance have been described. Here, we describe AFF3 (AF4/FMR2 family member 3), which encodes a nuclear protein with transactivation potential that confers tamoxifen resistance and enables estrogen-independent growth.

Methods: We investigated AFF3 expression in breast cancer cells and in clinical breast cancer specimens with western blot and Real-time PCR. We also examined the effects of AFF3 knockdown and overexpression on breast cancer cells using luciferase, tetrazolium, colony formation, and anchorage-independent growth assays in vitro and with nude mouse xenografting in vivo.
\end{abstract}

Results: AFF3 was overexpressed in tamoxifen-resistant tumors. AFF3 overexpression in breast cancer cells resulted in tamoxifen resistance, whereas RNA interference-mediated gene knockdown reversed this phenotype. Furthermore, AFF3 upregulation led to estrogen-independent growth in the xenograft assays. Mechanistic investigations revealed that AFF3 overexpression activated the ER signaling pathway and transcriptionally upregulated a subset of ER-regulated genes. Clinical analysis showed that increased AFF3 expression in $\mathrm{ER}^{+}$breast tumors was associated with worse overall survival.

Conclusions: These studies establish AFF3 as a key mediator of estrogen-independent growth and tamoxifen resistance and as a potential novel diagnostic and therapeutic target.

Keywords: AFF3, Breast cancer, Estrogen receptor-positive, Tamoxifen, Resistance

\section{Background}

Breast cancer is one of the three most frequently diagnosed malignancy and the second-leading cause of cancer-related death in women. Every year, an estimated 1 million new cases were diagnosed worldwide [1]. Breast cancer can be divided into subtypes according to histopathological features such as progesterone receptor (PR), estrogen receptor (ER), or erb-b2 receptor tyrosine kinase 2 (ERBB2 or HER2) status, and include ER-positive, HER2-positive, or triple-negative breast cancer [2]. ER-positive $\left(E R^{+}\right)$breast cancer constitutes around two-thirds of all breast

\footnotetext{
*Correspondence: 604793522@qq.com; wshenming@126.com

†Yawei Shi and Yang Zhao contributed equally to this work.

${ }^{1}$ The Department of Breast and Thyroid surgery, the First Affiliated Hospital of Sun Yat-sen University, 58\# Zhongshan Two Road, Guangzhou 510080, Guangdong, China

Full list of author information is available at the end of the article
}

malignancies [3]. The treatment options for such tumors include targeted anti-hormonal drugs, of which tamoxifen has been the first choice for decades, both in the adjuvant and the recurrent setting [4]. However, approximately $50 \%$ of patients with metastatic disease fail to respond, and practically all patients with metastasis with initially responsive tumors eventually develop acquired resistance, which becomes the cause of death $[5,6]$. It has been demonstrated that nuclear hormone receptor co-regulator differential expression $[7,8]$, growth factor signaling crosstalk [9-12], cyclin-dependent kinases (CDKs) [13], CDK inhibitors [14, 15], microRNA regulation [16], and in recent years, acquired $E R$ somatic mutations and alterations [1719], mediate tamoxifen resistance. Although the causes of tamoxifen resistance vary, the most predominant mechanisms are poorly understood. Further insight into the

(C) The Author(s). 2018 Open Access This article is distributed under the terms of the Creative Commons Attribution 4.0 International License (http://creativecommons.org/licenses/by/4.0/), which permits unrestricted use, distribution, and reproduction in any medium, provided you give appropriate credit to the original author(s) and the source, provide a link to the Creative Commons license, and indicate if changes were made. The Creative Commons Public Domain Dedication waiver (http://creativecommons.org/publicdomain/zero/1.0/) applies to the data made available in this article, unless otherwise stated. 
molecular mediators of tamoxifen and hormone therapy resistance would greatly impact the ability to target genes and pathways that could surmount drug resistance, and ameliorate clinical outcomes.

AFF3 (AF4/FMR2 family member 3, or LAF4) was first considered a lymphoid-specific gene; it is expressed and locate in the nuclear of B cells [20]. However, AFF3 mRNA is nearly imperceptible or in most cases completely absent in plasma cells and many other tissues [20]. AFF3 encodes a 1227 -amino acid protein that is presumed to play a role in transcriptional regulation, as it can directly bind to DNA and contains at least two domains with transactivation activity. These evidence indicated that $A F F 3$ may be a lymphoid lineage restricted gene with regulated function. AFF3 shares high sequence identity with the member of AF4/FMR2 family member, such as AFF1 (AF4/FMR2 family member 1, or AF4), AFF2 (AF4/FMR2 family member 2, or FMR2) and AFF4 (AF4/FMR2 family member 4, or MCEF) [21-23]. The AFF1 gene has been mapped to chromosome 4 and is the target of $\mathrm{t}(4 ; 11)$ translocation that occurs in approximately $50 \%$ of acute lymphoblastic leukemia (ALL) cases in children aged $<1$ year [24, 25], and results in fusion with the $M L L$ gene [26]. MLL and AFF4 fusion also occurs in infant ALL but at a much lower frequency. AFF3 and MLL fusion was observed in three independent cases of infant ALL of late [27-29]. Two cases resulted from $t(2 ; 11)$ translocations [27, 28], and the remaining case was due to ins(11,2) insertion [29]. These gene re-arrangement retained the transactivation domain of $A F F 3$, and $A F F 1$ and $A F F 4$, suggesting that deregulated expression of the downstream target genes is a common mechanism through which the fusion proteins contribute to oncogenesis. Interestingly, AFF3 is also deregulated in breast tumors [30]. However, its role in the development of breast cancer and the molecular mechanism underlying its involvement in tumorigenesis remain ambiguous.

In this study, we show that AFF3 is overexpressed in $\mathrm{ER}^{+}$human breast cancers, leading to tamoxifen resistance and estrogen-independent growth, and that patients with primary breast cancers with AFF3 overexpression have worse survival. Our study identifies $A F F 3$ as a new mediator of ER signaling and tamoxifen resistance with potential clinical implications.

\section{Methods}

\section{Cell culture}

Primary normal breast epithelial cell line, MCF-10A, were purchased from the American Type Culture Collection (ATCC, Manassas, VA, USA) and cultured according to the manufacturer's instruction. Breast cancer cell lines including BT549, HCC1937, MDA-MB231, MDA-MB468, MDA-MB361, T47D, MCF-7 and MDA-MB415, were obtained from the American Type Culture Collection, and grown in DMEM supplemented with $10 \%$ fetal bovine serum (FBS), within a humidified atmosphere containing $5 \% \mathrm{CO}_{2}$ at $37^{\circ} \mathrm{C}$.

\section{Establishment of resistant cell lines}

Parental MCF7 and T47D cells were continuously treated with tamoxifen (Tam, $10^{-7} \mathrm{M},>6$ months), and the resistant derivatives (TamRes) were selected when the initially sensitive cells resumed comparable growth to the parental cells.

\section{Tissue specimens}

Fresh human tissue samples including 10 breast cancer tissues and 3 normal mammary tissues were collected from the First Affiliated Hospital of Sun Yat-sen University, and were snap frozen and stored at liquid nitrogen until use. A cohort of 101 paraffin-embedded, archived breast cancer specimens was used to determine the clinical significance AFF3, these specimens were clinically diagnosed as breast cancer at from 2000 to 2008. The detail information was shown in Additional file 1: Table S1. For the use of all specimens for research purposes, prior patient's written informed consents and approval from the First Affiliated Hospital of Sun Yat-sen University.

\section{RNA extraction and real-time quantitative PCR}

Total cellular RNA was extracted using the TRIzol solution (Invitrogen), according to the manufacturer's protocol. Reverse transcription and Real-time PCR were performed using RT Real-Time ${ }^{\text {nx }}$ SYBR Green (Bio-Rad Laboratories, Berkeley, CA, USA). The housekeeping gene GAPDH was used as internal controls for mRNAs, respectively. The primers used were as follows: $A F F 3$ forward: $5^{\prime}$ - ACTC AACAGGATGATGGC - $3^{\prime}$, AFF3 reverse: $5^{\prime}$ - TGCCTAA AGTGTTCTGGATC -3'; GAPDH forward: 5' -GACTCAT GACCACAGTCCATGC-3', GAPDH reverse: 3'-AGAGG CAGGGATGATGTTCTG-5'.

\section{Western blotting}

Cellular proteins were prepared in sample buffer [62.5 mM Tris- $\mathrm{HCl}$ (pH 6.8), 10\% glycerol, 2\% SDS] and heated for $10 \mathrm{~min}$ at $100{ }^{\circ} \mathrm{C}$. Equal quantities of protein were electrophoresed through a $10 \%$ SDS/polyacrylamide gel and transferred to a PVDF membrane (Millipore, Billerica, MA, USA). The membranes were incubated with anti-AFF3 and anti-GAPDH antibodies (1:1,000; Cell Signaling Technology, Danvers, MA, USA), respectively.

\section{Oligonucleotides, siRNA, plasmids, retroviral infection and transfection}

For depletion of AFF3, siRNAs were synthesized and purified by RiboBio (The AFF3 siRNAs sequence were GGAAGAUGACCUUAAGCUAAG and CAGCUGUGU 
UGAAGAAAUAAU). Transfection of oligonucleotides and siRNAs were performed using Lipofectamine 3000 (Invitrogen), according to the manufacturer's protocol. The two human AFF3-targeting shRNA sequences were cloned into a pSuper-retro-puro vector to generate pSuper-retro-AFF3-RNAi (s). The cDNA of the human AFF3 gene was amplified by PCR and cloned into a pSin-EF2 lentiviral vector. Stable cell lines expressing AFF3 or AFF3 short hairpin RNAs (shRNAs) were selected by treatment of with $0.5 \mu \mathrm{g} / \mathrm{ml}$ puromycin for 10 days, beginning from $48 \mathrm{~h}$ after infection.

\section{Luciferase assay}

Cells were seeded in triplicate in 24-well plates and allowed to settle for $24 \mathrm{~h}$. ER luciferase reporter plasmid pGMER-Lu (YEASEN, SH, CHN) plus 1 ng pRL-TK Renilla plasmid were transfected into the cells using Lipofectamine 3000 Reagent (Invitrogen, Carlsbad, CA, USA). After $48 \mathrm{~h}$ transfection, cells were lysed and assayed for luciferase activity using Dual-Luciferase Reporter Assay kit (Promega) according to the manufacturer's instructions.

\section{3-(4, 5-Dimethyl-2-thiazolyl)-2, 5-diphenyl-2H-tetrazolium bromide (MTT) assay}

Cells were seeded in 96-well plates. $100 \mu \mathrm{l}$ of sterile MTT dye $(0.5 \mathrm{mg} / \mathrm{ml}$, Invitrogen) was added to the cells at the indicated time points, and the plate was incubated for another $4 \mathrm{~h}$ at $37{ }^{\circ} \mathrm{C} .150 \mu \mathrm{l}$ of dimethyl sulfoxide (DMSO) (Sigma) was then added and the absorbance was measured at $570 \mathrm{~nm}$, with $655 \mathrm{~nm}$ as the reference wavelength. Three independent experiments were performed and the data were presented as the mean \pm SD.

\section{Colony formation assay}

Cells were seeded in a 6 -well plate $\left(1 \times 10^{3}\right.$ cells per well $)$ and cultured for 10 days. The colonies were then fixed with $10 \%$ formaldehyde for $15 \mathrm{~min}$ and stained with $1.0 \%$ crystal violet for $5 \mathrm{~min}$. Three independent experiments were performed and the data were presented as the mean \pm SD.

\section{Anchorage-independent growth ability assay}

The bottom layer comprising 1\% complete medium agar (Sigma) mixture was poured into a well of the 6-well plate. After solidification, cells $\left(1 \times 10^{3}\right)$ were trypsinized and suspended in $2 \mathrm{ml}$ culture medium plus $0.3 \%$ agar, and then plated on top of the bottom layer. After 10 days incubation, colony sizes were measured with an ocular micrometer, and colonies greater than $0.1 \mathrm{~mm}$ in diameter were counted. The experiment was performed for independently three times for each cell line.

\section{Mouse xenografts}

Xenografts were performed using 5-week-old athymic nude female mice, which were randomly distributed into equal groups (5 mice per group) for each experiment. Mice were injected subcutaneously in the breast with $1 \times$ $10^{6}$ cells of the indicated cells. Mice were supplemented with estrogen pellets. Tumor volume (mean $\pm \mathrm{SD} ; \mathrm{mm}^{3}$ ) measurements were taken of the palpable tumors every week until week 5 when the mice were sacrificed. The National Institutes of Health Guide for the Care and Use of Laboratory Animals was followed in all experiments.

\section{Statistical analysis}

All data were expressed as the mean \pm SD. Student's $t$ test was used to evaluate the significance of the differences between two groups of data in all the pertinent experiments. The $P$ value reported was two-sided, and a value of $P<$ 0.05 was considered statistically significant.

\section{Results}

AFF3 upregulation in tamoxifen-resistant (TamR) breast cancers

AFF3 and SLC16A14 (solute carrier family 16 member 14) were upregulated across the subset of genes upregulated in the tamoxifen-resistant (TamR) derivative MCF-7 cell line and the subset of genes overexpressed in patients with incomplete response to chemotherapy (Fig. 1a). Notably, AFF3 expression was increased in luminal A and luminal B breast cancers, whereas SLC16A14 expression levels appeared unchanged (Additional file 2: Figure S1a). Quantitative real-time reverse transcription-PCR (qRT-PCR) and western blotting confirmed that AFF3 expression was increased in $\mathrm{ER}^{+}$breast cancer cell lines (Additional file 2: Figure S1b). Subsequently, four TamR cell models were developed independently from the $\mathrm{ER}^{+}$breast cancer cell lines MCF-7 and T47D, and the cell models all exhibited a stable phenotype of sustained cell growth in the presence of estrogen deprivation or tamoxifen (Additional file 2: Figure S1c). Interestingly, AFF3 protein was significantly increased in all four TamR cell models compared with the parental cells in both the MCF-7 and T47D cell lines (Fig. 1b). To verify that AFF3 upregulation was also present in actual human breast cancers, we evaluated specimens from three normal breast tissues and $10 \mathrm{ER}^{+}$ breast cancer tissues. The breast cancer tissues had documented tamoxifen response (patients 1, 2, 3, 4, and 5) and tamoxifen resistance (patients 6, 7, 8, 9, and 10). qRT-PCR and western blotting showed that AFF3 was upregulated in the $\mathrm{ER}^{+}$breast cancer tissues compared to the normal breast tissues. Furthermore, the results confirmed that AFF3 expression was increased remarkably in the TamR specimens compared to the tamoxifen-responsive samples (Additional file 2: Figure S1d; Fig. 1c). These results demonstrate that AFF3 overexpression is present in $\mathrm{ER}^{+}$breast cancers and can increase after the development of tamoxifen resistance. 
a

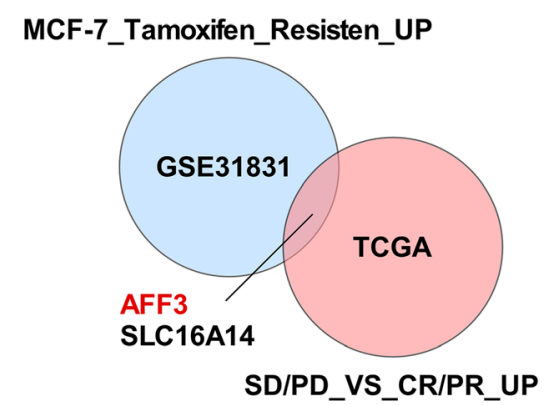

b

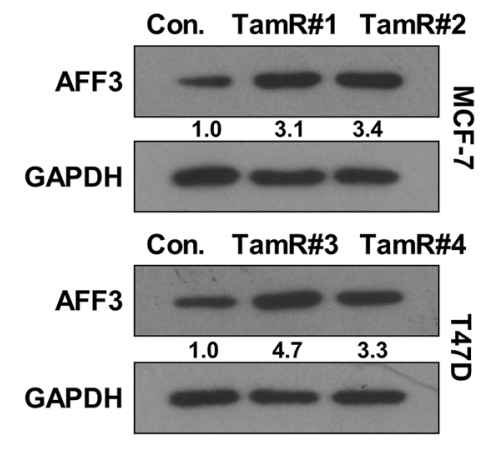

C

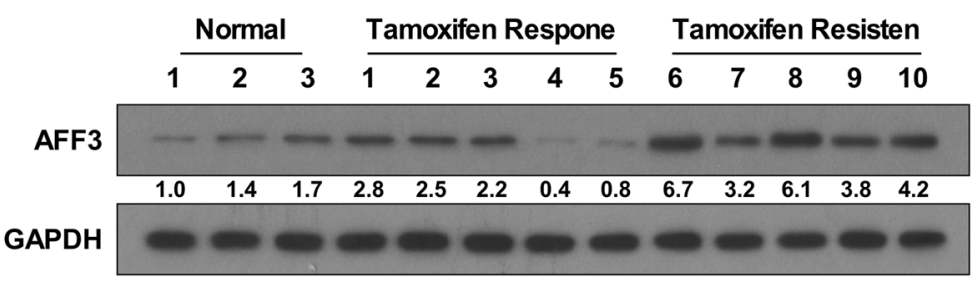

Fig. 1 AFF3 upregulation in TamR breast cancers. a Venn diagrams showing the overlapping proteins upregulated across two models $(P<0.05)$. b Western blotting performed on whole cell lysates demonstrating increased AFF3 protein levels in the TamR cell lines. GAPDH antibody was used as the loading control. c Western blotting of AFF3 expression in breast cancer tissues compared with noncancerous breast tissues

\section{AFF3 overexpression led to tamoxifen resistance; gene knockdown reversed it}

To determine whether increased AFF3 gene expression in the TamR clones would mediate tamoxifen resistance, we overexpressed the full-length $A F F 3$ complementary DNA (cDNA) in the MCF-7 and T47D cell lines. Western blotting verified AFF3 overexpression in both the TamR and AFF3-overexpressing clones compared to the empty vector control cell lines (Fig. 2a). We then exposed the cells to estrogen and tamoxifen for 7 days. Both the TamR and AFF3-overexpressing clones demonstrated a TamR phenotype (Fig. $2 \mathrm{~b}$ and $\mathrm{c}$ ).

We next determined whether $A F F 3$ gene knockdown by RNA interference could reverse tamoxifen resistance. This reversal was accomplished with short hairpin RNA (shRNA) constructs against the AFF3 transcript in TamR cell lines. We generated two constructs: shRNA\#1 and shRNA\#2, which were effective in reducing AFF3 expression when stably expressed in the TamR clones (Fig. 3a). We then assessed tamoxifen sensitivity by growing the AFF3 knockdown and control cell lines in the presence of estrogen and tamoxifen. The shRNA knockdown reversed the tamoxifen resistance compared with the control TamR clones (Fig. $3 \mathrm{~b}$ and c). However, $A F F 3$ knockdown in the parental control cell lines did not improve tamoxifen sensitivity (Additional file 3: Figure S2a). Taken together with the cDNA overexpression experiments, these results strongly suggest that AFF3 overexpression can mediate a TamR phenotype.

\section{AFF3 overexpression led to a TamR phenotype in vivo} We next found that AFF3 upregulation markedly increased the anchorage-independent growth ability in AFF3-overexpressing clones compared with the parental control cell lines. Subsequently, knockdown of AFF3 expression in the TamR clones decreased their anchorageindependent growth ability (Fig. 4a).

To further characterize AFF3 mediation of the TamR phenotype, we assessed TamR cell proliferation in xenografts in athymic nude mice. It is well established that MCF-7 cells require estrogen supplementation to grow as xenografts. Control mice inoculated with parental MCF-7 cells did not develop xenograft tumors in the presence of both estrogen and tamoxifen, but the mice inoculated with the AFF3-overexpressing clones did (Additional file 2: Figure S2b). Later, we inoculated female athymic nude mice with the TamR clones as well as their AFF3 knockdown counterparts with or without tamoxifen. There was growth inhibition in vivo following tamoxifen exposure of the TamR clones with AFF3 shRNA knockdown as compared with the parental TamR clones (Fig. 4b). These results strongly suggest that $A F F 3$ overexpression can lead to a TamR phenotype.

\section{AFF3 overexpression activated the ER signaling pathway} and increased the expression of ER-regulated genes MCF-7 and T47D cells are frequently used models for $\mathrm{ER}^{+}$estrogen-dependent breast cancer cell growth. However, the TamR clones demonstrated relatively reduced 


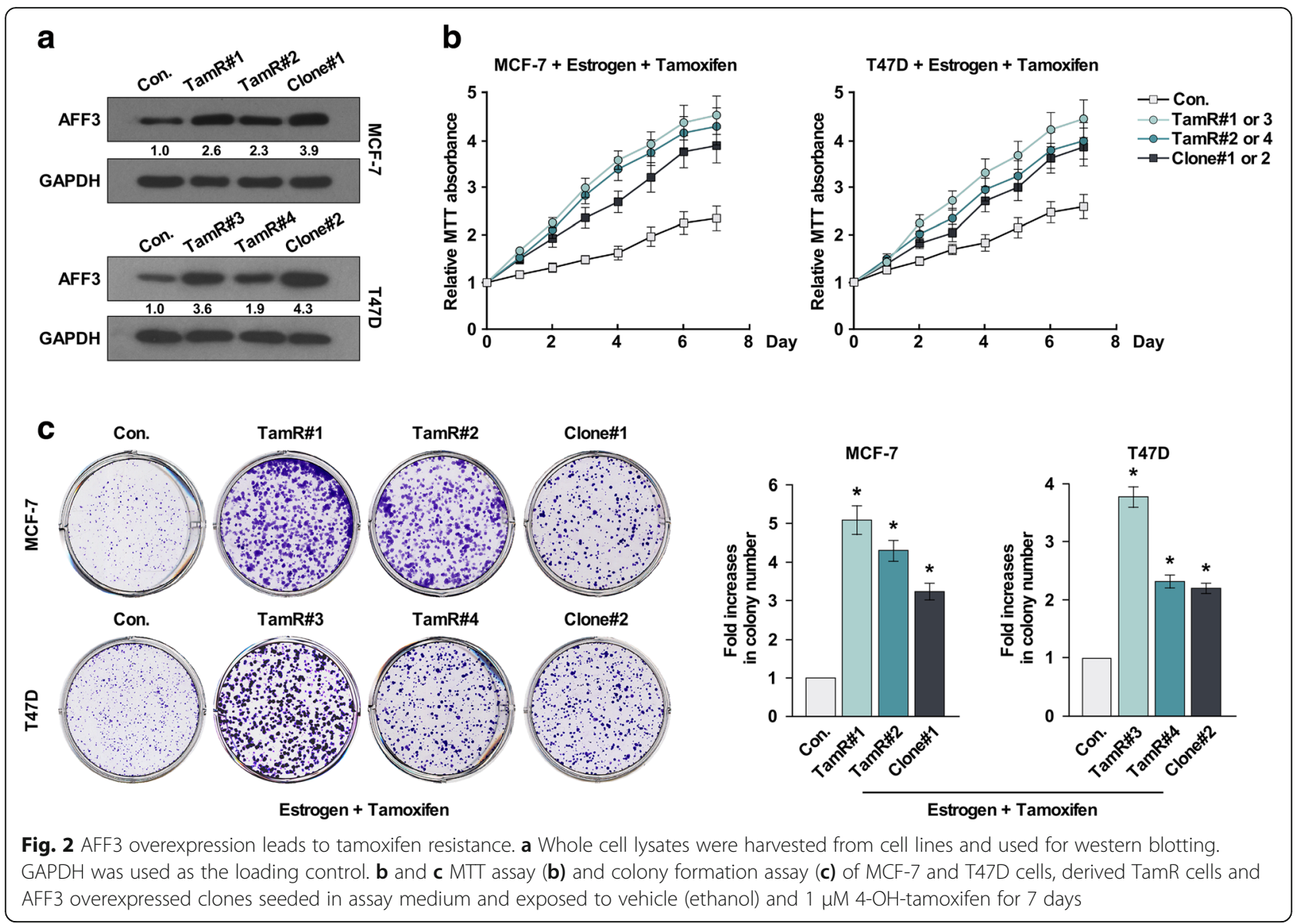

response to exogenous estrogens and indeed were capable of cell proliferation in the absence of estrogen and tamoxifen. We suspected that AFF3 overexpression may function similarly as an ER coactivator and that its overexpression may lead to increased expression of the ER-regulated genes even in the absence of estrogen. We initially surveyed selected candidate ER-regulated genes using RT-PCR, and demonstrated that, following estrogen inhibition by tamoxifen, gene expression was increased in the AFF3-overexpressing clones (Fig. 5a). Conversely, AFF3 depletion in the TamR clones also reduced the expression of the ER-regulated genes (Fig. 5a). Several growth-promoting genes and enzymes were differentially expressed in the $A F F 3$ varied clones relative to the control cells, suggesting that $A F F 3$ diversification may affect ER signaling pathway activity (Fig. 5b).

\section{Primary luminal breast cancers with AFF3 overexpression had worse prognosis}

To determine the clinical significance of $A F F 3$ overexpression in human breast cancers, we assessed AFF3 protein levels through immunohistochemical staining on an independent cohort of 101 formalin-fixed, paraffin-embedded tumor tissues from patients with liminal breast cancer
(Additional file 1: Table S1). AFF3 positivity (Additional file 1: Table S2) was observed in 95 patients; Cox regression analyses showed a shorter time to progression (TTP) both in univariate (hazard ratio $[\mathrm{HR}]=2.634 ; 95 \%$ confidence interval $[95 \% \mathrm{CI}]: 2.14-4.16 ; P=0.010)$ and multivariate $(\mathrm{HR}=2.396 ; 95 \% \mathrm{CI}: 1.136-5.058 ; P=0.022)$ analyses (Additional file 1: Table S3). The presence of AFF3 was significantly associated with shorter survival time in both univariate $(\mathrm{HR}=2.449 ; 95 \% \mathrm{CI}: 2.14-4.16 ; P=0.027)$ and multivariate $(\mathrm{HR}=2.680 ; 95 \% \mathrm{CI}: 1.187-6.052 ; P=0.018)$ Cox regression analyses (Additional file 1: Table S4). In addition, survival analysis was performed on patients stratified according to AFF3 levels, with TTP as the endpoint. A significant difference was observed between patients with high AFF3 protein levels (Fig. 6a). AFF3 was positively associated with faster disease progression in luminal breast cancer $(P=0.008)$ (Fig. 6b). An overall survival KaplanMeier estimate demonstrated a statistically significant difference between patients whose tumors had high AFF3 compared with those that did not $(P=0.023)$ (Fig. 6c). These results provide additional evidence that $A F F 3$ overexpression is biologically relevant, has prognostic significance for $\mathrm{ER}^{+}$breast cancers, and may serve as a predictive marker and future target of therapy. 


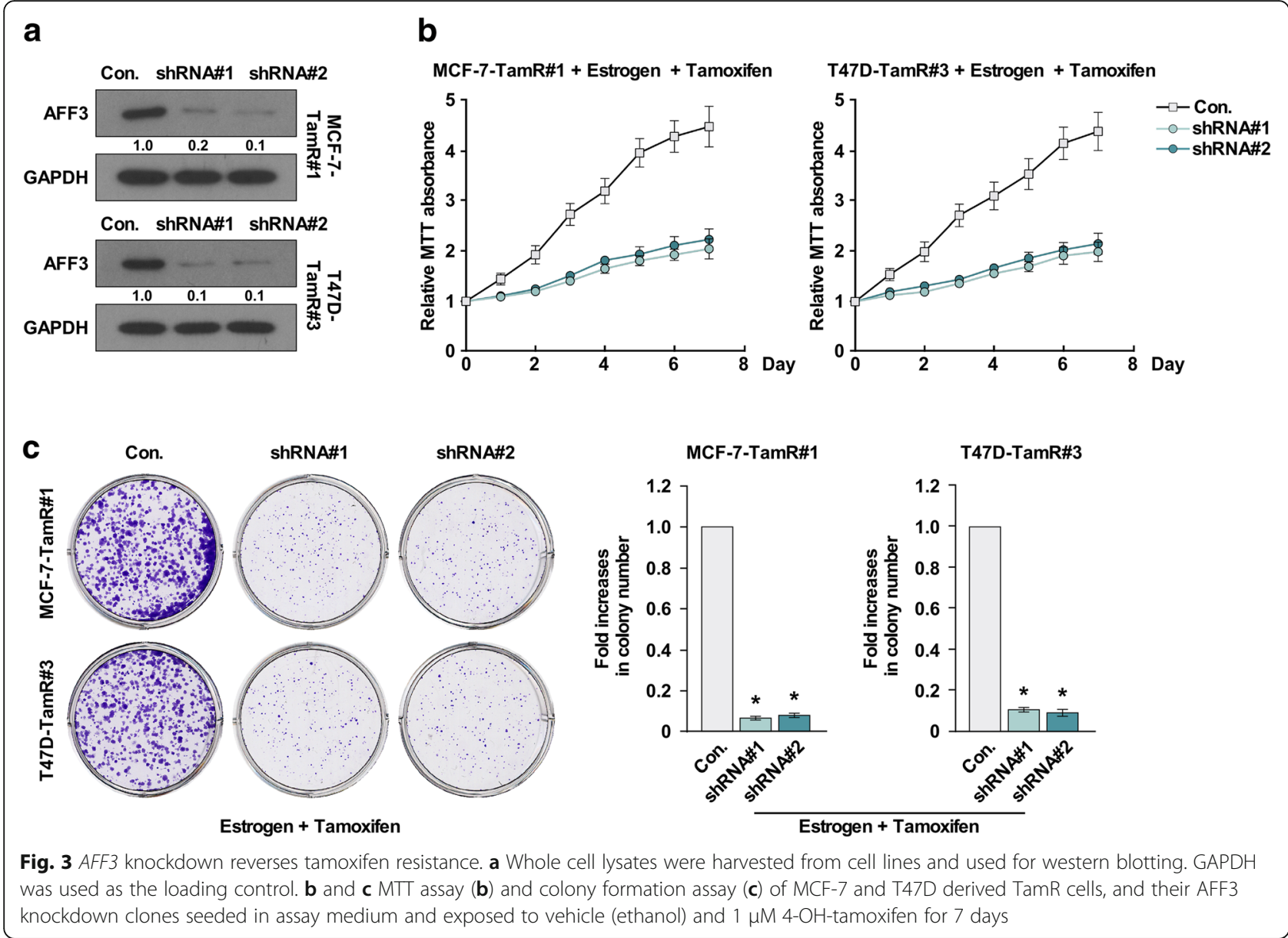

\section{Discussion}

Approximately $75 \%$ of breast tumors express ER $\alpha$, and patients with breast cancer with ER $\alpha$-positive tumors generally receive endocrine therapy, such as receptor antagonists (antiestrogens), including tamoxifen or fulvestrant, or aromatase inhibitors such as anastrozole or letrozole that inhibit ligand (17 $\beta$-estradiol) production [31-33]. Notably, tamoxifen has been used to treat both pre- and post-menopausal patients with breast cancer for over 40 years and remains a cornerstone of endocrine therapy for breast cancer. However, intrinsic or acquired resistance to tamoxifen presents a particular clinical concern. Many initially responsive tumors develop resistance to these endocrine therapies, and overall, more women die from $\mathrm{ER}^{+}$breast cancer than from any other molecular subtype [34]. Although there has been much progress in treating $\mathrm{ER}^{+}$breast cancers with endocrine therapies, drug resistance remains a daunting clinical issue. Actually, interest in understanding and uncovering the genetic effectors of endocrine therapy resistance has been renewed with the recent discovery of $E R$ mutations and translocations found at relatively high frequency in metastases but that are rare in primary breast tumors. Obviously, these studies suggest that $E R$ mutations/alterations emerge after treatment and that there is progression in endocrine therapies. However, they do not throw light on all mechanisms of hormone resistance, and the ability to identify additional mediators of resistance remains of high clinical importance.

The present study demonstrates for the first time that AFF3 mediates tamoxifen resistance and estrogen-independent growth in breast cancer. We conclude this based on the following: First, independently derived TamR MCF-7 and T47D clones overexpressed AFF3. Second, there was $A F F 3$ upregulation in specimens from patients with tamoxifen-resistant breast cancer. Third, AFF3 upregulation in two separate $\mathrm{ER}^{+}$breast cancer cell lines led to tamoxifen resistance, and gene knockdown by stable shRNA reversed this phenotype. Fourth, AFF3 upregulation led to estrogen-independent growth in vivo and upregulated both ER-regulated and non-ER-regulated growth-promoting genes. Finally, patients with $\mathrm{ER}^{+}$(luminal A/B) primary breast tumors with $A F F 3$ upregulation had significantly worse outcome, in comparison with patients whose primary breast tumors did not upregulate AFF3. Our results suggest that the latter may have de 

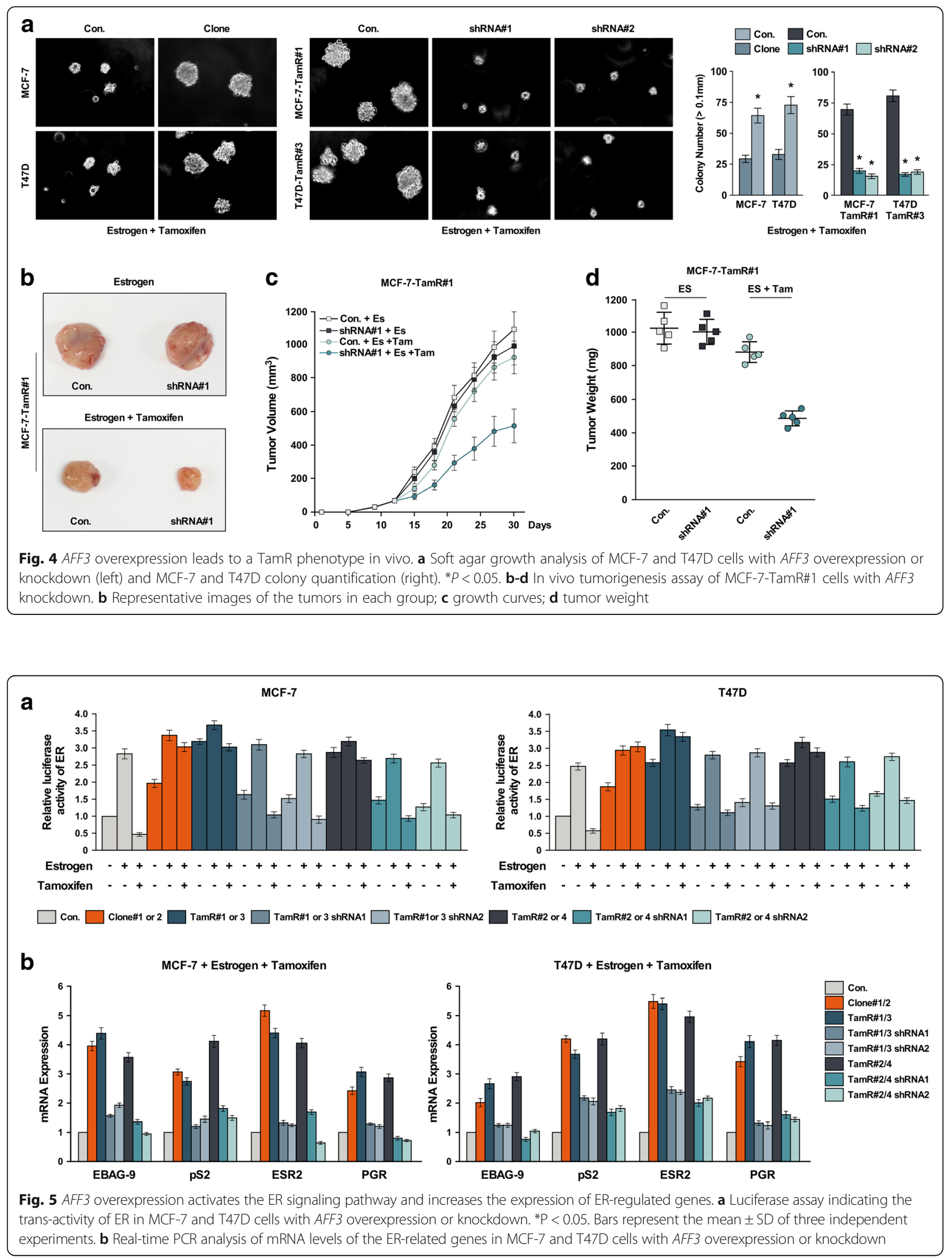

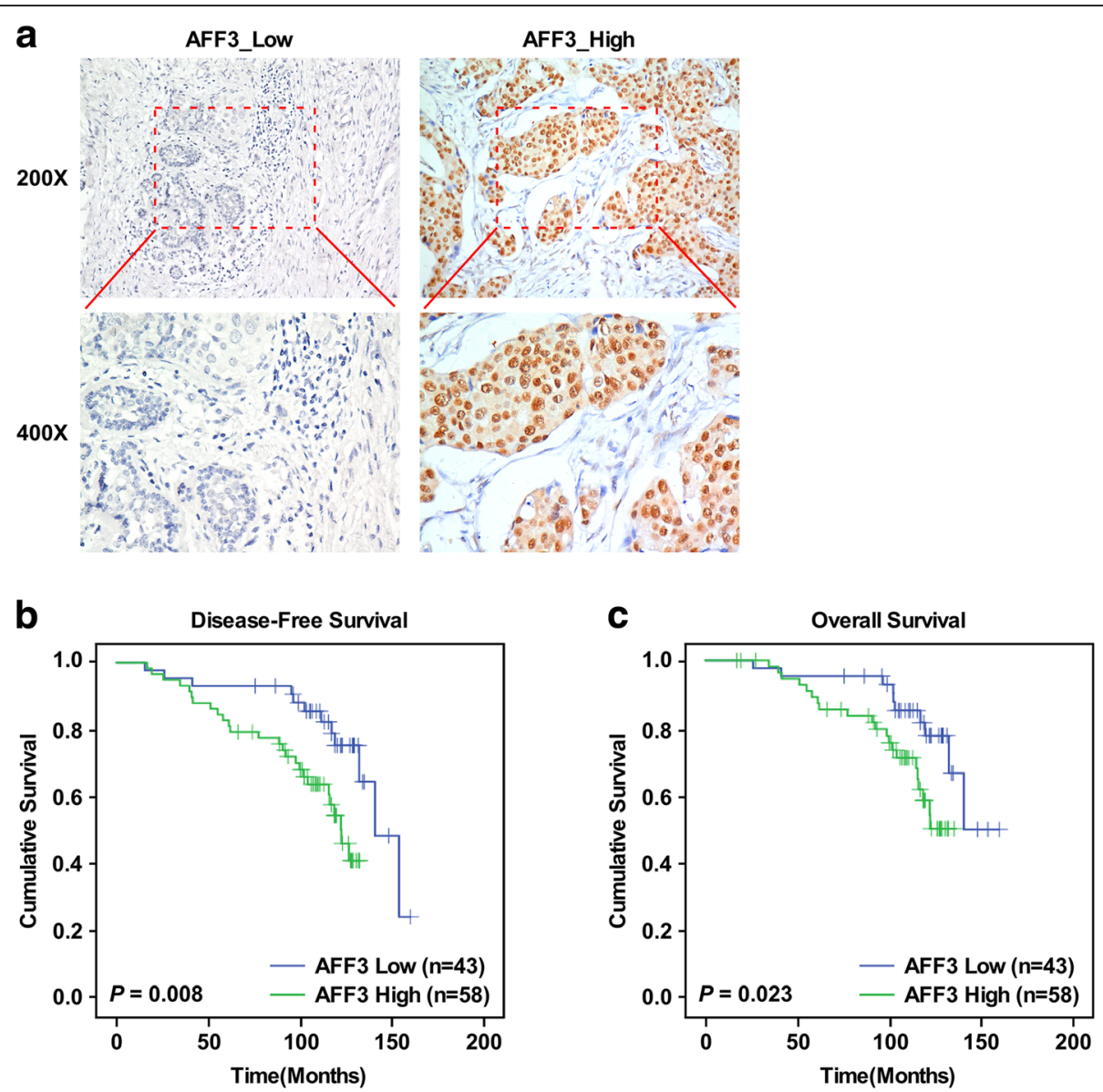

Fig. 6 Primary luminal breast cancers with AFF3 overexpression have worse prognosis. a Immunohistochemical staining of AFF3 expression in breast cancer tissues. $\mathbf{b}$ and $\mathbf{c}$ Kaplan-Meier survival curves of the relapse-free survival (b) and overall survival (c) of patients with breast cancer with high or low AFF3 protein levels

novo resistance to tamoxifen and perhaps to other endocrine therapies.

The precise physiological function of AFF3 is not known, but it has been postulated to play a role in lymphoid cell development [20]. The pathological effect of $M L L-A F F 3$ is also not known, but the fact that the transcriptional activation domain of $A F F 3$, as well as other members of the AF4 gene family, is retained in the fusion protein strongly suggests that altered target gene expression is an important step towards ALL pathology. Aberrant expression of the AFF3 gene itself in mammary epithelial cells could have a similar effect and thereby contribute to the pathogenesis of breast cancer. We demonstrate that $A F F 3$ is upregulated in breast cancers, leading to tamoxifen resistance and estrogen-independent growth, which are properties more consistent with an oncogene. As a cancer-specific fragile site, it is possible that AFF3 is lost without any selective pressure for its preservation. However, for $\mathrm{ER}^{+}$breast cancers treated with tamoxifen, the frangibility of this locus allows for overexpression, prompting the emergence of drug-resistant clones. Our results suggest that tamoxifen-insensitive patients have a higher frequency of $A F F 3$ overexpression, which may mediate estrogen-independent growth. Lack of experimental samples limited our study, as it is not easy to gather metastatic biopsies from patients with clinical follow-up. Regardless, the significantly worse outcomes in patients whose primary breast cancers upregulate $A F F 3$, including the large data set from the TCGA (The Cancer Genome Atlas) study, is accord with the idea that $A F F 3$ may herald intrinsic resistance to tamoxifen therapy with a more aggressive cancer phenotype.

The molecular mediators of endocrine resistance have recently come into much sharper focus, including: i) mutant ER that are constitutively active in the absence of estrogen and more difficult to suppress with conventional endocrine treatment; ii) the upregulation/amplification of ER coactivators that can greatly increase ER activity; iii) the upregulation of alternative oncogenic signaling pathways, including several growth factors and growth factor receptors, resulting in greatly enhanced protein kinase pathway activity; and iv) the amplification 
or overexpression of gene regions encoding oncogenic proteins and transcription factors, promoting cancer cell survival, invasiveness, and metastasis. Interestingly, the luciferase assays indicated that $A F F 3$ exerts a profound impact on ER transcriptional activity activation; in a public dataset, we found that AFF3 expression is related to the ER pathway, suggesting that AFF3 may cause tamoxifen failure by reactivating ER. However, the underlying mechanism by which AFF3 activates ER transcriptional activity and sustains its activity remains unclear, and we are currently investigating it.

\section{Conclusion}

We report AFF3 gene overexpression in TamR cell models. With the recent interest and success of epigenetic therapies for cancer treatment, it is tempting to speculate that AFF3 may be a druggable protein and that its overexpression may help identify patients whose tumors have intrinsic resistance to tamoxifen and a high-risk phenotype. Therefore, the discovery of a previously unidentified gene, $A F F 3$, and its functional role in drug resistance, may lead to improved systemic therapies and predictive markers for treating $\mathrm{ER}^{+}$breast cancers.

\section{Additional files}

Additional file 1: Table S1. Clinicopathological characteristics of BC patient samples. Table S2. The expression of AFF3 in Breast cancer. Table S3. Correlation between AFF3 expression and clinicopathologic characteristics of Breast cancer. Table S4. Univariate and multivariate analyses of various prognotic parameters in patients with BC Cox-regression analysis. Table S5. Univariate and multivariate analyses of various prognotic parameters in patients with BC Cox-regression analysis. (DOCX 27 kb)

Additional file 2: Figure. S1. a Expression level of AFF3 and SLC116A14 in breast cancer tissues compared with noncancerous breast tissues ( $n=$ 627; TCGA). b Real-time PCR analysis and western blot analysis of AFF3 expression in normal breast cell MCF10A and breast cancer cell lines, including BT-549, HCC1937, MDA-MB231, MDA-MB468, MDA-MB361, T47D, MCF-7, MDA-MB-415. c MTT assay of MCF-7 and T47D cells, derived TamR cells seeded in assay medium and exposed to vehicle (ethanol) or $1 \mu \mathrm{M}$ 4-OH-tamoxifen for 7 days. $\mathbf{d}$ Real-time PCR analysis of AFF3 expression in breast cancer tissues compared with noncancerous breast tissues. (TIF $1817 \mathrm{~kb}$ )

Additional file 3: Figure. S2. a Colony formation assay of MCF-7 and T47D cells, derived AFF3 knock down clones seeded in assay medium and exposed to vehicle (ethanol) and $1 \mu \mathrm{M} 4-\mathrm{OH}$-tamoxifen for 7 days. b Representative images of the tumors in each group, growth curves and tumor weight. (TIF 8999 kb)

\section{Abbreviations}

AFF1 or AF4: AF4/FMR2 family member 1; AFF2 or FMR2: AF4/FMR2 family member 2; AFF3: AF4/FMR2 family member 3; AFF4 or MCEF: AF4/FMR2 family member 4; ALL: acute lymphoblastic leukemia; ATCC: the American Type Culture Collection; CDKs: cyclin-dependent kinases; DMSO: dimethyl sulfoxide; ER: estrogen receptor; $\mathrm{ER}^{+}$: estrogen receptor-positive; ERBB2 or HER2: erb-b2 receptor tyrosine kinase 2; MTT: 3-(4, 5-Dimethyl-2-thiazolyl)-2, 5-diphenyl-2H-tetrazolium bromide; PR: progesterone receptor;

TamR: tamoxifen-resistant
Availability of data and materials

All data generated or analyzed during this study are included in this published article (and its Additional files).

\section{Authors' contributions}

YS and SW conceived and designed this study. $Y Z, Y Z, N A, N S$ and RY performed the experiments. $Y Z$ analyzed the data. $Y S$ and $Y L$ wrote the manuscript. All authors read the approved the final manuscript.

\section{Ethics approval and consent to participate}

For the use of clinical tissues for research purposes, the prior consent of the patients and approval from the Institutional Research Ethics Committee of the First Affiliated Hospital of Sun Yat-sen University were obtained. All animal experiments were approved by and conducted in accordance with the guidelines of the Institutional Animal Care and Use Committee of the First Affiliated Hospital of Sun Yat-sen University.

Consent for publication

All authors approved of the manuscript and consented to its publication.

\section{Competing interests}

The authors declare that have no competing interests.

\section{Publisher's Note}

Springer Nature remains neutral with regard to jurisdictional claims in published maps and institutional affiliations.

\section{Author details}

${ }^{1}$ The Department of Breast and Thyroid surgery, the First Affiliated Hospital of Sun Yat-sen University, 58\# Zhongshan Two Road, Guangzhou 510080, Guangdong, China. ${ }^{2}$ The Department of Vascular surgery, the Third Affiliated Hospital of Sun Yat-sen University, 600\# Tianhe Road, Guangzhou 510000, Guangdong, China. ${ }^{3}$ The Department of General surgery, the Seventh Affiliated Hospital of Sun Yat-sen University, 628\# Zhenyuan Road, Shenzhen 518100, Guangdong, China.

Received: 23 May 2018 Accepted: 5 October 2018

Published online: 16 October 2018

\section{References}

1. Ginsburg O, Bray F, Coleman MP, Vanderpuye V, Eniu A, Kotha SR, Sarker M, Huong TT, Allemani C, Dvaladze A, et al. The global burden of women's cancers: a grand challenge in global health. Lancet. 2017;389(10071):847-60.

2. Vuong D, Simpson PT, Green B, Cummings MC, Lakhani SR. Molecular classification of breast cancer. Virchows Arch. 2014;465(1):1-14.

3. Ignatiadis M, Sotiriou C. Luminal breast cancer: from biology to treatment. Nat Rev Clin Oncol. 2013:10(9):494-506.

4. Jordan VC. Selective estrogen receptor modulation: concept and consequences in cancer. Cancer Cell. 2004;5(3):207-13.

5. Ring A, Dowsett M. Mechanisms of tamoxifen resistance. Endocr Relat Cancer. 2004:11(4):643-58.

6. Gradishar WJ. Tamoxifen—what next? Oncologist. 2004;9(4):378-84.

7. Shang Y, Brown M. Molecular determinants for the tissue specificity of SERMs. Science. 2002;295(5564):2465-8.

8. Reiter R, Oh AS, Wellstein A, Riegel AT. Impact of the nuclear receptor coactivator AIB1 isoform AIB1-Delta3 on estrogenic ligands with different intrinsic activity. Oncogene. 2004;23(2):403-9.

9. Kurokawa $\mathrm{H}$, Lenferink AE, Simpson JF, Pisacane PI, Sliwkowski MX, Forbes JT, Arteaga CL. Inhibition of HER2/neu (erbB-2) and mitogen-activated protein kinases enhances tamoxifen action against HER2-overexpressing, tamoxifen-resistant breast cancer cells. Cancer Res. 2000;60(20):5887-94.

10. Osborne CK, Bardou V, Hopp TA, Chamness GC, Hilsenbeck SG, Fuqua SA, Wong J, Allred DC, Clark GM, Schiff R. Role of the estrogen receptor coactivator AIB1 (SRC-3) and HER-2/neu in tamoxifen resistance in breast cancer. J Natl Cancer Inst. 2003:95(5):353-61.

11. Fagan DH, Uselman RR, Sachdev D, Yee D. Acquired resistance to tamoxifen is associated with loss of the type I insulin-like growth factor receptor: implications for breast cancer treatment. Cancer Res. 2012;72(13):3372-80.

12. Jin $K$, Kong $X$, Shah $T$, Penet MF, Wildes F, Sgroi DC, Ma XJ, Huang $Y$, Kallioniemi A, Landberg G, et al. The HOXB7 protein renders breast cancer 
cells resistant to tamoxifen through activation of the EGFR pathway. Proc Natl Acad Sci U S A. 2012;109(8):2736-41.

13. Iorns E, Turner NC, Elliott R, Syed N, Garrone O, Gasco M, Tutt AN, Crook T, Lord Cl, Ashworth A. Identification of CDK10 as an important determinant of resistance to endocrine therapy for breast cancer. Cancer Cell. 2008;13(2):91-104.

14. Planas-Silva MD, Weinberg RA. Estrogen-dependent cyclin E-cdk2 activation through p21 redistribution. Mol Cell Biol. 1997;17(7):4059-69.

15. Abukhdeir AM, Vitolo MI, Argani P, De Marzo AM, Karakas B, Konishi H, Gustin JP, Lauring J, Garay JP, Pendleton C, et al. Tamoxifen-stimulated growth of breast cancer due to 21 loss. Proc Natl Acad Sci U S A. 2008;105(1):288-93.

16. Bergamaschi A, Katzenellenbogen BS. Tamoxifen downregulation of miR451 increases 14-3-3zeta and promotes breast cancer cell survival and endocrine resistance. Oncogene. 2012;31(1):39-47.

17. Li S, Shen D, Shao J, Crowder R, Liu W, Prat A, He X, Liu S, Hoog J, Lu C, et al. Endocrine-therapy-resistant ESR1 variants revealed by genomic characterization of breast-cancer-derived xenografts. Cell Rep. 2013;4(6):1116-30.

18. Merenbakh-Lamin K, Ben-Baruch N, Yeheskel A, Dvir A, Soussan-Gutman L, Jeselsohn R, Yelensky R, Brown M, Miller VA, Sarid D, et al. D538G mutation in estrogen receptor-alpha: a novel mechanism for acquired endocrine resistance in breast cancer. Cancer Res. 2013;73(23):6856-64.

19. Jeselsohn R, Yelensky R, Buchwalter G, Frampton G, Meric-Bernstam F, Gonzalez-Angulo AM, Ferrer-Lozano J, Perez-Fidalgo JA, Cristofanilli M, Gomez $\mathrm{H}$, et al. Emergence of constitutively active estrogen receptor-alpha mutations in pretreated advanced estrogen receptor-positive breast cancer. Clin Cancer Res. 2014;20(7):1757-67.

20. Ma C, Staudt LM. LAF-4 encodes a lymphoid nuclear protein with transactivation potential that is homologous to AF-4, the gene fused to MLL in $\mathrm{t}(4 ; 11)$ leukemias. Blood. 1996;87(2):734-45.

21. Gu Y, Nakamura T, Alder H, Prasad R, Canaani O, Cimino G, Croce CM, Canaani E. The t(4;11) chromosome translocation of human acute leukemias fuses the ALL-1 gene, related to Drosophila trithorax, to the AF-4 gene. Cell. 1992;71(4):701-8.

22. Taki T, Kano H, Taniwaki M, Sako M, Yanagisawa M, Hayashi Y. AF5a31, a newly identified AF4-related gene, is fused to MLL in infant acute lymphoblastic leukemia with ins(5;11)(q31;q13q23). Proc Natl Acad Sci U S A. 1999;96(25):14535-40.

23. Gecz J, Gedeon AK, Sutherland GR, Mulley JC. Identification of the gene FMR2, associated with FRAXE mental retardation. Nat Genet. 1996;13(1):105-8.

24. Rowley JD. Rearrangements involving chromosome band 11Q23 in acute leukaemia. Semin Cancer Biol. 1993;4(6):377-85.

25. Heerema NA, Sather HN, Ge J, Arthur DC, Hilden JM, Trigg ME, Reaman GH. Cytogenetic studies of infant acute lymphoblastic leukemia: poor prognosis of infants with t(4;11) - a report of the Children's Cancer group. Leukemia. 1999;13(5):679-86

26. Imamura T, Morimoto A, Ikushima S, Kakazu N, Hada S, Tabata Y, Yagi T, Inaba T, Hibi S, Sugimoto T, et al. A novel infant acute lymphoblastic leukemia cell line with MLL-AF5q31 fusion transcript. Leukemia. 2002;16(11):2302-8.

27. Hiwatari M, Taki T, Taketani T, Taniwaki M, Sugita K, Okuya M, Equchi M, Ida K, Hayashi Y. Fusion of an AF4-related gene, LAF4, to MLL in childhood acute lymphoblastic leukemia with $\mathrm{t}(2 ; 11)(\mathrm{q} 11 ;$;23). Oncogene. 2003;22(18):2851-5.

28. von Bergh $A R$, Beverloo HB, Rombout $P$, van Wering ER, van Weel $M H$, Beverstock GC, Kluin PM, Slater RM, Schuuring E. LAF4, an AF4-related gene, is fused to MLL in infant acute lymphoblastic leukemia. Genes Chromosomes Cancer. 2002;35(1):92-6.

29. Bruch J, Wilda M, Teigler-Schlegel A, Harbott J, Borkhardt A, Metzler M. Occurrence of an MLL/LAF4 fusion gene caused by the insertion ins(11; 2)(q23;q11.2q11.2) in an infant with acute lymphoblastic leukemia. Genes Chromosomes Cancer. 2003:37(1):106-9.

30. To MD, Faseruk SA, Gokgoz N, Pinnaduwage D, Done SJ, Andrulis IL. LAF-4 is aberrantly expressed in human breast cancer. Int J Cancer. 2005;115(4):568-74.

31. Burstein HJ, Lacchetti C, Griggs JJ. Adjuvant endocrine therapy for women with hormone receptor-positive breast Cancer: American Society of Clinical Oncology clinical practice guideline update on ovarian suppression summary. J Oncol Pract. 2016;12(4):390-3.

32. Turner NC, Neven P, Loibl S, Andre F. Advances in the treatment of advanced oestrogen-receptor-positive breast cancer. Lancet. 2017;389(10087):2403-14.

33. Harbeck N, Gnant M. Breast cancer. Lancet. 2017;389(10074):1134-50.

34. Droog M, Beelen K, Linn S, Zwart W. Tamoxifen resistance: from bench to bedside. Eur J Pharmacol. 2013;717(1-3):47-57.

\section{Ready to submit your research? Choose BMC and benefit from:}

- fast, convenient online submission

- thorough peer review by experienced researchers in your field

- rapid publication on acceptance

- support for research data, including large and complex data types

- gold Open Access which fosters wider collaboration and increased citations

- maximum visibility for your research: over $100 \mathrm{M}$ website views per year

At BMC, research is always in progress.

Learn more biomedcentral.com/submissions 